\title{
STEAM education: student learning and transferable skills
}

\author{
Marja G. Bertrand and Immaculate K. Namukasa \\ Department of Curriculum Studies, Western University Faculty of Education, \\ London, Canada
}

\begin{abstract}
Purpose - Globally, interdisciplinary and transdisciplinary learning in schools has become an increasingly popular and growing area of interest for educational reform. This prompts discussions about Science, Technology, Engineering, Arts and Mathematics (STEAM), which is shifting educational paradigms toward art integration in science, technology, engineering and mathematics (STEM) subjects. Authentic tasks (i.e. realworld problems) address complex or multistep questions and offer opportunities to integrate disciplines across science and arts, such as in STEAM. The main purpose of this study is to better understand the STEAM instructional programs and student learning offered by nonprofit organizations and by publicly funded schools in Ontario, Canada.
\end{abstract}

Design/methodology/approach - This study addresses the following research question: what interdisciplinary and transdisciplinary skills do students learn through different models of STEAM education in nonprofit and in-school contexts? We carried out a qualitative case study in which we conducted interviews, observations and data analysis of curriculum documents. A total of 103 participants (19 adults - director and instructors/teachers - and 84 students) participated in the study. The four STEAM programs comparatively taught both discipline specific and beyond discipline character-building skills. The skills taught included: critical thinking and problem solving; collaboration and communication; and creativity and innovation.

Findings - The main findings on student learning focused on students developing perseverance and adaptability, and them learning transferable skills.

Originality/value - In contrast to other research on STEAM, this study identifies both the enablers and the tensions. Also, we stress ongoing engagement with stakeholders (focus group), which has the potential to impact change in teaching and teacher development, as well as in related policies.

Keywords STEAM, STEM and arts, STEM and creativity, Art integration, Integrated curriculum, Art-based curriculum, STEAM and Canada, Transferrable skills, Transdisciplinary, 21st century skills, Domain-general skills, Workplace skills

Paper type Research paper

\section{Introduction}

Globally, interdisciplinary and transdisciplinary learning in schools has become an increasingly popular and growing area of interest for educational reform. This prompts discussions about Science, Technology, Engineering, Arts and Mathematics (STEAM), which is shifting educational paradigms toward art integration in science, technology, engineering and mathematics (STEM) subjects. According to Reeves et al. (2004), learning opportunities for students should include "authentic tasks" set in a real-world context. Authentic tasks consist of ill-defined problems, complex or multistep questions, multiple ways to approach a problem and subtasks that integrate across disciplines (Armory, 2014). The main purpose of this study is to better understand the learning that results from STEAM

(C) Marja G. Bertrand and Immaculate K. Namukasa. Published in Journal of Research in Innovative Teaching \& Learning. Published by Emerald Publishing Limited. This article is published under the Creative Commons Attribution (CC BY 4.0) licence. Anyone may reproduce, distribute, translate and create derivative works of this article (for both commercial and non-commercial purposes), subject to full attribution to the original publication and authors. The full terms of this licence may be seen at http:// creativecommons.org/licences/by/4.0/legalcode

The research assistantship for this article was supported by Western University and SSHRC.

Received 16 January 2020 Revised 10 March 2020 Accepted 14 March 2020

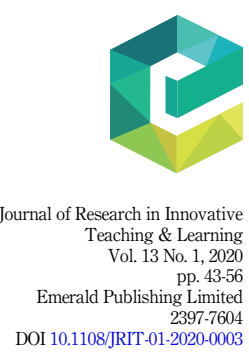


JRIT

13,1

instructional programs. This study has implications for designing and teaching learning tasks in STEAM programs. This study addresses the research questions: what interdisciplinary and transdisciplinary skills do students learn from engaging in STEAM programs offered by nonprofit organizations and by publicly funded schools? What are students observed to learn when they engage in tasks offered in these programs?

Curriculum models and the transdisciplinary approach to STEAM

Industrial, political and educational leaders rally behind initiatives that support the development of students' workforce competencies, such as by "'promoting deeper' learning through skills such as problem solving and collaboration” (Allina, 2018, p. 80). STEM and STEAM education scholars agree that STEAM initiatives enable students to transfer their knowledge across disciplines and thus to creatively solve problems in a different context, both in the classroom and out-of-school (Gess, 2017; Liao, 2016). According to Hughes (2017), students need these character-building or transferable skills: "students need to develop and apply for successful learning, living and working" (p. 102). STEAM teaches students skills such as "critical thinking and problem solving; collaboration and communication; and creativity and innovation" (Liao et al., 2016, p. 29) that can be transferred to another context. Transdisciplinary approaches to STEAM education are highly valued by both the teacher and the student because they allow the student to view the problem or design process from multiple angles or different perspectives that can be applied to a real-world context (Costantino, 2018). Empirical research on STEAM education, however, is in its infancy and little research has compared more than two STEAM programs or models. Our research compares four STEAM programs and focuses particularly on the nature and learning outcomes of models of STEAM education in those programs.

\section{Theoretical framework}

The theoretical frameworks adopted for this study are multilayered to analyze three levels: task design, STEAM models and interdisciplinary learning experiences. For the level of task design, we adopt the "low floor, high ceiling, wide walls" lens. Gadanidis (2015) utilizes this term to describe learning environments when designing and implementing tasks that integrate mathematics and coding in the classroom. The goal of the tasks he designs is to enhance the students' overall learning experience and make it more meaningful through curiosity and creativity. This learning environment provides multiple entry points, multiple ways to approach a problem and multiple representations of these activities, so that students of all ages and abilities can participate (Gadanidis et al., 2011). To analyze pedagogy, curriculum and instruction models in the four STEAM programs we take into account critical work by previous researchers. A critical lens has been adopted by researchers such as Blikstein (2013) to critique efforts that limit students' engagement on interdisciplinary learning tasks such as surface or basic learning of how to use technology tools and skills. Kafai et al. (2019) support adopting frameworks that cross boundaries and focus on cognitive skills, social participation, critical-social justice approaches and on learning using computer technology. According to Blikstein (2013), educators should avoid "quick demonstration projects" that are aesthetically pleasing to the students but require little effort. Instead they should promote "multiple cycles of design" so that students create complex solutions and products, design "powerful interdisciplinary projects" that narrow the gap between disciplines, "contextualize the learning in STEM [/STEAM]". This makes abstract concepts more meaningful and engaging, and generates an "environment that values multiple ways of working” (p. 18). Thirdly, we use three of Kolb and Kolb's (2005) guiding principles of experiential learning theory as a framework to analyze the interdisciplinary and transdisciplinary student learning in the STEAM programs. The main guiding principles of 
experiential learning theory according to Kolb and Kolb (p. 3) are the following: learning is best conceived as a process, learning is a holistic process of adaptation to the world and learning is the process of creating knowledge. Kolb and Kolb's framework resonates with Papert's work. Papert's (1980) constructionism theory of learning is foundational to Maker education, which is guiding the adoption of the broader Maker culture and makerspaces (Halverson and Sheridan, 2014) in schools. Kolb and Kolb's work also resonates with the emphasis on the processes developed in design-based learning and the learning of transferable skills.

\section{Research design}

This research was a qualitative case study. According to Yin (2004), a case study focuses on a bounded-system and sheds light on a situation. The main purpose of a case study is to focus on a particular phenomenon, such as a process, event, person or other area of interest (Gall et al., 2007). A collective case study (Stake, 2005), in which the researcher selects more than one representative case, enables more theoretical generalizations (Cousin, 2005).

We took a sample of four different STEAM programs in Ontario, Canada, two nonprofit organizations and two in-school research sites, with a total of 103 participants, 19 adults and 84 students. We collected data from document analyses, observations and interviews. The lead author observed the participants during the lessons. She also conducted conversational interviews using open-ended questions (Arthur et al., 2012). Table 1 summarizes the settings of the research sites and the environment. At each of the research sites three to eight classes or sessions were observed. Most of the classes observed, apart from In-School 1, depended upon the teacher/instructor's availability. The curriculum documents analyzed consisted of course and program overview, collaborative meeting notes, unit plans and lesson plans for each of the sites. The data analyzed included: interview transcripts, observation data written by one of the researchers and analysis of curriculum document photocopies. A focus group discussion was also conducted with four elementary classroom teachers. At this discussion, one of the researchers presented preliminary results on the curriculum and instructional models of STEAM. The lead researcher then orchestrated discussion on how classroom teachers viewed such models as meeting their goals. The focus group discussion was audio recorded, transcribed and analyzed.

\begin{tabular}{ll}
\hline & Environment \\
\hline $\begin{array}{l}\text { Non- } \\
\text { Profit 1 }\end{array}$ & $\begin{array}{l}\text { A one room STEAM lab/center with a large } \\
\text { space divided by movable walls. Space set up } \\
\text { for small group work, with desks, chairs and } \\
\text { workstations as well as floor mats }\end{array}$ \\
Non- & $\begin{array}{l}\text { Multiple rooms set up as a computer laboratory } \\
\text { for students to work individually or in pairs at } \\
\text { desks. Stations (e.g. the Laser/Wood cutter } \\
\text { room) were located in different rooms }\end{array}$ \\
In- & $\begin{array}{l}\text { Its learning environment is set in the Maker Lab } \\
\text { located in the Library Learning Commons. It is } \\
\text { a STEAM center/lab with work benches and } \\
\text { stations for students } \\
\text { The Makerspace has both stationary and } \\
\text { mobile stations. Some of the lessons happened } \\
\text { School } 2\end{array}$ \\
$\begin{array}{l}\text { outside of the Makerspace, such as the Science } \\
\text { and Technology Application Centre (STAC) } \\
\text { room or in their regular classroom }\end{array}$
\end{tabular}

Research site

Urban STEAM center/lab in a metropolitan area. Caters to K-7 children and has programs for teens/adults. Offers paid programs: weekend, after school, PD, school hours and summer workshops. Staff members consist of a director, instructors and volunteers

Urban public school in a metropolitan area catering to K-8 students. The STEAM program consists of one teacher librarian and selected school teachers 


\section{JRIT \\ 13,1}

\section{Results}

This paper presents the research results from the analysis of observation data, interview transcripts, curriculum document photocopies and focus group transcripts.

\section{Student learning and transferable skills}

The curriculum documents that were shared with the researchers from each of the STEAM programs showed that students learned character-building skills, which are transferable to other real-life contexts, such as post-secondary education and the workforce. The focus group participants referred to these as 21st century skills. These encompass skills learned beyond the STEAM content curriculum. During the observation of the sessions, the lead researcher noticed and took field notes on these skills. Participants also commented about these skills when responding to interview questions on the benefits of STEAM education. At In-School 1, for example, the teacher librarian commented on these skills:

Interviewer: What would you say are the learning objectives for this STEAM program?

Teacher Librarian: I'm all about giving them skills to express their ideas, transferable skills so they can take with them to the next grade level. Keep practicing those skills, keep developing those skills and hopefully bring some of those skills together in unconventional ways.

Similarly, the director at Non-Profit 1 wanted his students to "look at the world around them as the place that can be changed by their ideas ... [and] make this city [world] a better place somehow." At Non-Profit 2, instructor 2 explained that "giving them the tools to have a better life essentially and work life, that's where adding technology and adding these new features, new STEAM learning comes from." The director, instructors and teachers are empowering the students to make a difference in their community and the world. The director of the STEAM program said, "what we are trying to do is to empower people [kids] to feel like ... they can make a difference in the world" (Non-Profit 1). The findings suggest that, by teaching these character-building skills, the instructor/teacher can empower these students to solve realworld problems, to have more opportunities in the future and to have an impact on the world.

The analysis of the curriculum documents revealed that those documents of the in-school research sites were more detailed and aligned with specific standards in the Ontario curriculum than those of the nonprofit sites, which were less detailed and not tightly based on the curriculum standards.

Curiosity. All sites included an initial stage that built on students' curiosity and interest in the lesson or session.

Both nonprofit cases used games and storytelling to pique the interest and curiosity of their students at the beginning of an activity. At Non-Profit 1, the director explained that "the first stage is play so that they can experiment with the technology [to] get an idea of what it can do, [and] get excited about it." At Non-Profit 2, students were given the opportunity by the instructors to tinker and play with the craft materials and technologies to spark their interest and curiosity as they researched, designed and created objects. For example, students played with an apparatus made out of Popsicle sticks and syringes in which they learned how changes in pressure can make the contraption move.

In contrast, both in-school cases used inquiry-type questions to get students to wonder, and to stir their imagination and pique their curiosity at the beginning of an activity. In the post-observation interview, the special education teacher expressed that the "inspiring piece [is]... doing these type of learning activities ... you are activating kids' natural curiosity, their natural interest in figuring out how things work and how they can make things better" (InSchool 2). Both in-school cases allowed students the opportunity to tinker as they explored a new technology before using it to solve a problem or to create a digital or concrete object, such as a robot or a multimedia work of art. 
Oral communication. All sites included opportunities for students to discuss their making processes verbally.

Non-Profit 1 and 2 facilitated group discussions with their students and prompted them to answer inquiry-type questions as a class. Non-Profit 1 also provided students with several opportunities to communicate their ideas verbally. Students used oral communication skills when discussing the features of their product in a video commercial or when sharing what they learned about the design of their product in a video presentation.

At the in-school research sites, students documented their "making process" of the prototype and expressed their thoughts verbally. At In-School 1, the students documented every stage of the making process in a video to capture their observations, creations and group discussions. The teacher librarian commented that the intent of the documentation was to "drive their thinking forward," and this documentation appeared to deepen the students' understanding as they reflected on, articulated and then shared their thoughts and ideas.

Written communication. The two nonprofit sites provided students with the opportunity to communicate their ideas in writing at different stages of the making process.

Non-Profit 1 clearly indicated specific tasks in their lesson plans where students communicated their ideas in writing. For example, when coding in the visual programming language Scratch, students were asked to write a story by creating a plan and a sequence of events for their characters. During the planning stage of their projects, students sketched their ideas and expressed their thoughts through writing and drawing as seen in Plate 1. NonProfit 2, similarly, allowed their students the freedom to make a plan or sketch their ideas and prompted them to use multiple media. For example, some students wrote out their plan, while others designed them digitally, or used modeling clay to create their 3D figures.

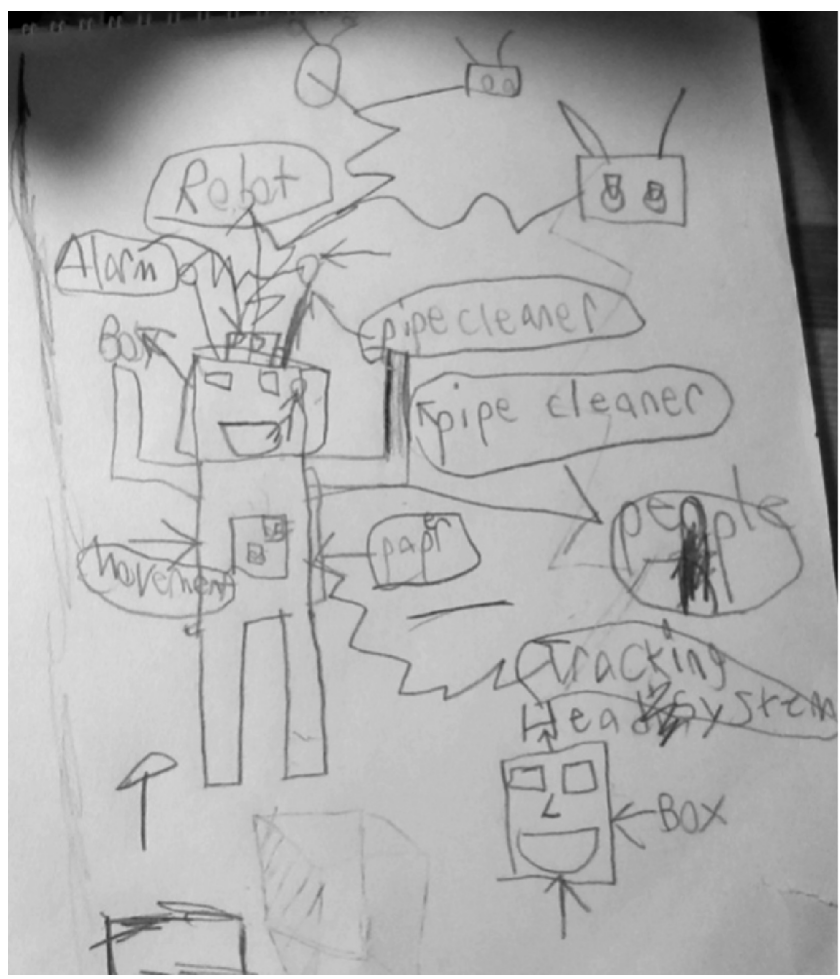

Plate 1.

At Non-Profit 1, students expressed their thoughts through writing and drawing to describe the robot's functions 
JRIT

13,1

48

In-School 1 encouraged students to document the making process by writing, and completing a handout provided by the teacher librarian. The handout provided the following writing prompts: to write their answer to the inquiry questions about the activity, to write notes resulting from their Internet search and to write out a plan for their design (as seen in Plate 2). In-School 2 used nontraditional ways of getting students grades 1-3 to write, which included using sticky notes and index cards. The teacher librarian then encouraged the students to further organize and review their ideas by articulating their thoughts into categories and subcategories. At In-School 2, the Grade 5 students were, specifically, prompted to complete a $\log$ during the design-inquiry lesson. During this lesson, the students were given a hand-out, which documented every stage of the design-inquiry process, to complete. It appeared that the two in-school cases provided students with more opportunities to communicate in written form and share their thinking since students were given a handout and student log to record their ideas and thoughts, as seen in Plate 2. In contrast, Non-Profit 2 instructors did not explicitly mention in the curriculum documents or during the lessons observed that students should document or write, but allowed their students the freedom to make a plan or sketch their ideas using multiple media, such as writing, modeling (e.g. clay) and/or designing them digitally.

Perseverance and adaptability. At all sites the adults interviewed spoke about how they engaged students in specific activities to develop perseverance.

At Non-Profit 1, the instructors used picture books to get kids (6-9 years old) to discuss selected transferable skills such as adaptability and persistence. These picture books allowed students to visually understand the skills and to discuss their views such as on their experiences where these skills could have been helpful. Students, for example, discussed their views on making mistakes. The instructor at Non-Profit 1 said she wanted her students to "not be afraid of making mistakes and trying new things." When asked "what type of

Plate 2.

At In-School 1, students wrote information in the collecting Ideas section to answer the inquirytype questions that would help them build and program

their robot

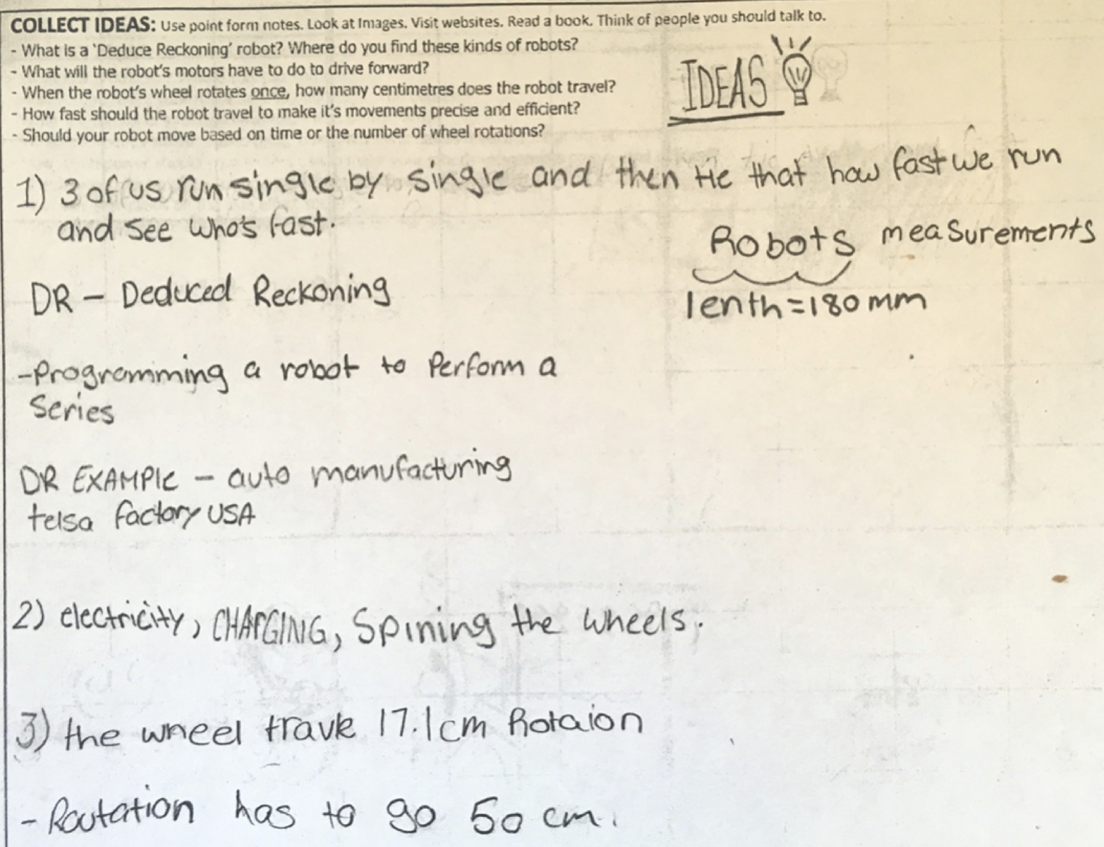


curriculum or instructional models do you commonly use in the STEAM lab/center?”, the director and instructor at Non-Profit 1 mentioned that they created a learning environment where failure and iteration were built into the lesson or session.

To develop perseverance among students both nonprofit and in-school cases got students to plan, design, make a prototype, test, redesign and, when the prototype did not work, to repeat the design-inquiry process (see Plate 3 ). At the in-school and nonprofit sites, 12 out of 15 adult participants mentioned perseverance during the interviews. For example, when a teacher librarian was asked what the students learned she answered, "developing mindsets, developing perseverance and grit in an openness to try new things" (In-School 2). The teacher librarian at In-School 1 talked about the goal to "grow persistence and [to] keep a positive frame of mind." Similarly, a Grade 5 teacher mentioned that he "saw a lot of [perseverance]... and problem solving even with robotics, they had to code the robot to move around a shape and to escape the maze through using trial and error and you know they had to keep going and not give up" (In-School 1).

Collaboration. Both nonprofit cases encouraged students to collaborate and work as a team when they were given group challenges. For example, in the spaghetti challenge, students had to build the tallest free-standing structure using spaghetti, and in the class mascot challenge students had to design an original mascot character for their team using wood and the laser cutter (seen in Plate 4). The two in-school sites provided students with the opportunity to work collaboratively in groups on a project or on a mini-assignment that took more than one day to complete. In contrast, the group challenges at the nonprofit sites were used as a team-building activity in which students were given a limited amount of time and resources to complete the task. For example, Non-Profit 2 gave the students specific constraints, such as 40 sticks of spaghetti, 5 marshmallows, 1 strip of tape and $10 \mathrm{~min}$, to

Prototype: test and redesign

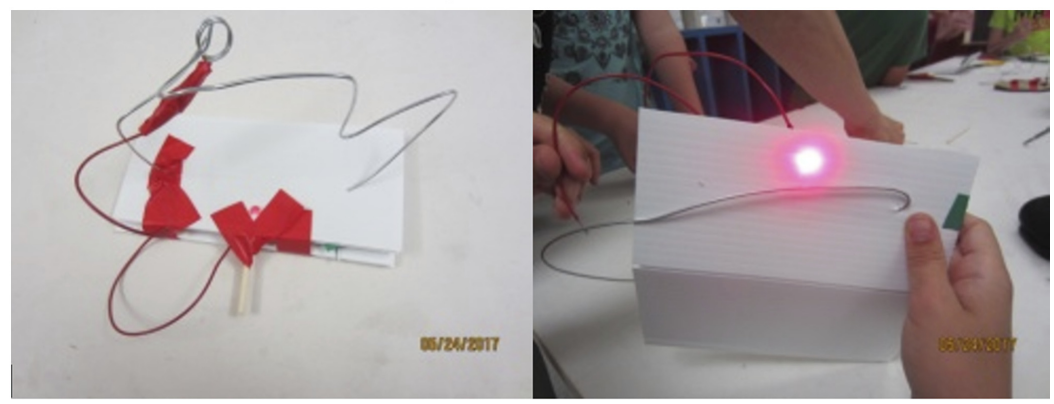

Final product:

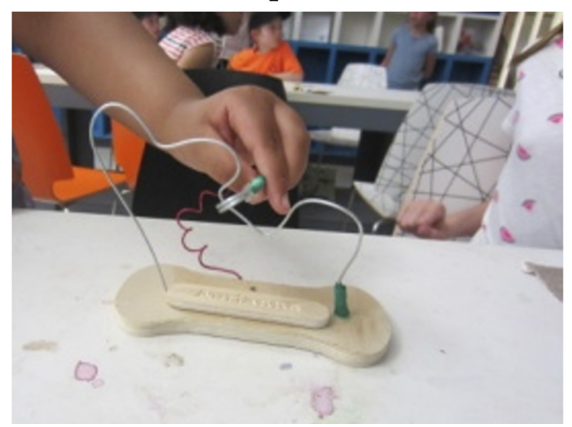

Plate 3.

At Non-Profit 2, students designed and built a prototype to make their own buzz wire game. Students then changed the materials used to make a more efficient version of the game 


\section{JRIT 13,1}

Plate 4.

As a class, students sketched, designed and created a team mascot using the laser cutter

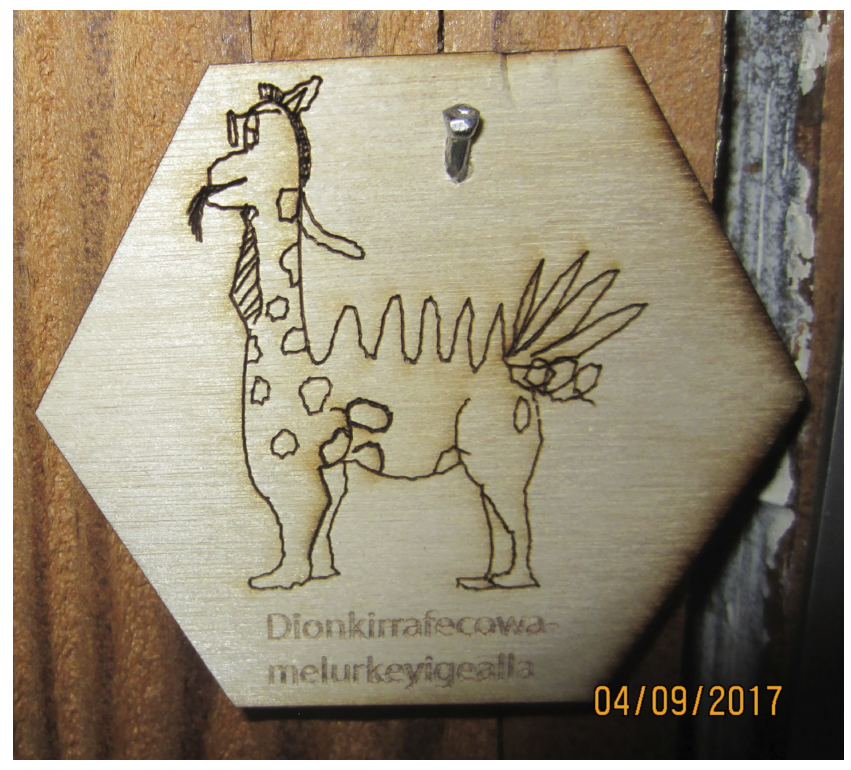

complete the spaghetti challenge. In the interview, the director at Non-Profit 1 explained that their goal was to teach the students "personal skills ... which are collaboration, knowledge about themselves, ... [knowledge] about their own personal strengths and challenges" so they can effectively work as a team.

The in-school STEAM programs provided students with several opportunities to work in groups whether they were designing a robot, creating a pattern in Minecraft, programming a robot such as LEGOEV3, Ozobot or Sphero to move around a perimeter or move to the beat of a song. At In-School 1, a Grade 2 teacher expressed that she "think[s] that collaboration is absolutely key." A Grade 5 teacher found that when kids did not know what to do "after they explore[d] and [then were given opportunities to] collaborate with their own teammates ... they would create these amazing things" (In-School 1).

Critical thinking. Non-Profit 1 was not as concerned with the product as much as the process. The director said that one of the student learning objectives "is critical thinking, so that they can make a plan ... and critically analyze [their] plan to make sure that it is awesome and doable, so the design always comes before the building" (Non-Profit 1). At Non-Profit 2, students were given various tasks that would prompt them to use critical-thinking and problem-solving skills. For example, when Grade 7 and 8 students were creating conditional (if-then) statements in a programming language for novices such as Scratch or Java script, they would have to use problem-solving skills to write the code and critical-thinking skills to check for errors (debug) in their program when it was unsuccessful.

At the in-school sites, the learning objectives for two of the STEAM disciplines, science and mathematics, appeared to enhance students' opportunities to use critical-thinking and problem-solving skills. Each lesson at In-School 2 focused on a question or set of questions that prompted students to brainstorm and think about a real-life context, such as "How might we get Georgie [the robot] home and describe the path?" Students were given the opportunity to answer questions such as this one using multiple approaches. Further, students used unplugged methods (e.g. methods with no digital or screen technology, such as string stories, drawings, LEGO creations and arrow diagrams), as seen in Plate 5 , to focus their minds on 
and solve selected problems. In this example, Kindergarten and Grade 1 students had to think critically about direction, measurement, angles and scale factor and the distances that were represented on the path they defined for the robot. These students also used different digital technologies, such as Ozobots and Beebots, to code and enact the path that they had described as Georgie's path home. Thus, these students had to further use problem-solving skills to transfer their unplugged solution to the solution simulated by programming a robot to follow a specific path.

\section{Summary of student learning and transferable skills}

Every research site encouraged the students to tinker and experiment with the technology through play and discovery. During our observations, all students learned characterbuilding skills that were exemplified in the curriculum documents, such as curiosity and imagination, oral and written communication, perseverance and adaptability, collaboration, and critical thinking and problem-solving. Specifically, Non-Profit 1 and In-School 2 used storytelling and answering inquiry-type questions to engage their students and to activate the students' natural curiosity. Non-Profit 1 and 2 used games to fuel the students' interest, imagination and curiosity. Both in-school cases also used the Ontario curriculum when creating some of the specific objectives and inquiry-type questions. Non-Profit 1 and both inschool cases, 3 of 4 sites, chose to document the "making process" through video. This allowed students to communicate and share their thinking. The two in-school cases allowed students to both share their thinking verbally in a video and in writing in a student log. The purpose of documenting the "making process" was to drive students thinking forward by reflecting on what worked well, what needed to be changed and what could have been done differently.

At the nonprofit and in-school sites, students learned to develop persistence and adaptability when going through the design-inquiry process of plan-design-make-testredesign and repeat. At Non-Profit 1, the director and instructor created a learning environment in which students were not afraid to make mistakes. To encourage

\section{STEAM education}

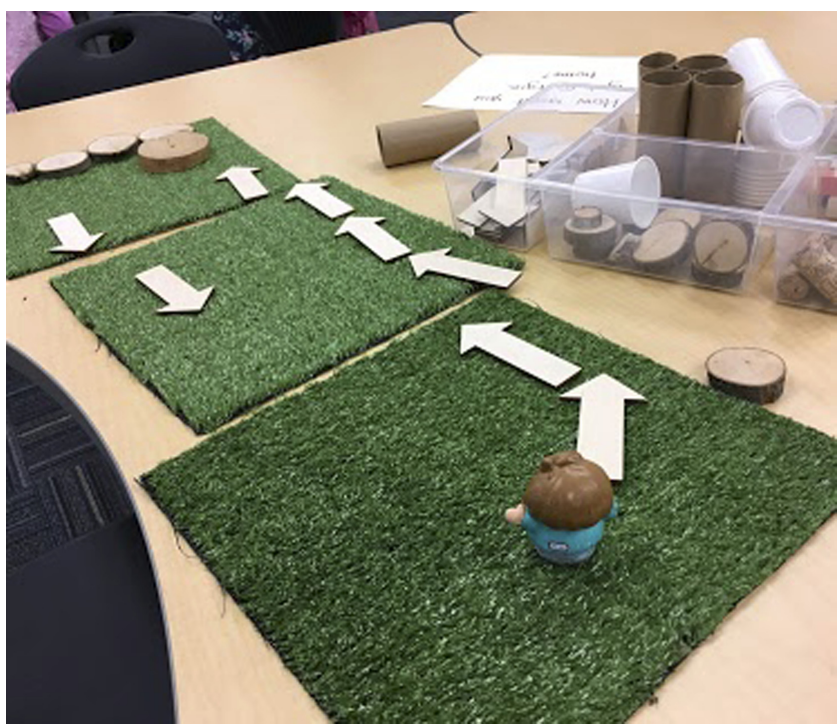

Plate 5.

At In-School 2, students made an arrow diagram or collage 
JRIT

13,1

perseverance, failure and iteration were built into the lesson or session at Non-Profit 1 . All four research sites created group activities and encouraged students to collaborate with one another, whether students were working on a team challenge or a group project. Through collaboration, students learned their strengths and "after they explore[d] and collaborate[d] with their own teammates and then they would create these amazing things" (Grade 5 Teacher, In-School 1). These character-building skills were also mentioned in the curriculum documents and were "all about giving [students] skills to express their ideas, transferable skills" that can be used in a different context or to solve a different problem.

\section{Classroom teachers' views on student learning and transferable skills}

At the focus group with the four elementary classroom teachers, they commented on the pedagogy, curriculum and instruction as well as on the STEAM education's goals on student learning at the four research sites. When responding to the focus group discussion prompt, "In what ways could some of the models/stages presented be used to meet curriculum and teaching goals in a school classroom?" Teacher $\mathrm{C}$ answered:

Well we're preparing them for a better world. The world I grew up in was a factory world. Some of my fellow students went to jobs where they would do the same job every day for the rest of their lives and that's not the case anymore... I really like the authentic experiences and the rich tasks. I think that in our world today there are a lot of problems to be solved.

Teacher $\mathrm{D}$ in the focus group gave an example of these authentic and rich tasks:

Whether it regards sustainability or you know just, compassion in the world, solving some of these food and hunger issues, water resources issues and I think that preparing our students to connect with their learning is a viable skill that they can take with them in the future. You know [for example, collaboration and communication skills] where there are so many different entry-level projects and contests [in these STEAM learning activities], where students are really creating things that are being used in our community and are being used to solve real-world problems. And I think that's when I find my kids the most engaged when they can actually see that thinking.

During the focus group discussion, teachers identified challenges they face when developing some of the character-building skills. For example, Teacher B described one of her challenges as "growth mindset [perseverance]... That's one of the biggest challenges when we're doing STEAM activities... it's like an unwillingness to try again or change the design even if it's not working." Teacher D suggested "that's why I think that it needs to start in the younger years and this idea of building, designing and trying again, being resilient, knowing how many prototypes something takes before [you get the final product] in the real world ... You are never going to get a final product without going through that messy process of try-fail-start again" and repeat. This idea of failure and reiteration of a lesson seemed to resonate with the focus group participants. They all knew that it was important for student learning and was built into both the design-inquiry process and the STEAM activities at the research sites.

At all the research sites, students learned character-building skills. These skills seemed transferable because they could be used in real life: in high school, in post-secondary education and, eventually, in the workforce. When the teachers were asked "what are some of the greatest benefits in STEAM education?", they saw the benefits of how the STEAM tasks connected to students' real lives, to the world in which students find themselves, and to how students may prepare for future jobs. A Grade 5 teacher at In-School 1 said "I think the biggest thing is it just speaks to kids; this is their language right now. This is their world if you think about like future job opportunities, this is like $21^{\text {st }}$ Century learning for kids, this is what they know and what they are interested in."

Instructor 2 at Non-Profit 2 said "giving them the tools to have a better life essentially and work life, that's where adding technology and adding these new features, new STEAM 
learning comes from." The director at Non-Profit 1 wanted his students to "think about, think of, look at the world around them as the place that can be changed by their ideas ... [and] make this city a better place somehow." Teachers (and students in their interviews) in the STEAM programs considered the skills being learned as valuable and realistic. The director of the STEAM program said "what we are trying to do is to empower [kids] to feel like they can have control over their lives, they can make things that they want, ... that they need. They can make a difference in the world and these tools of technology and science and engineering are really a great way to do that" (Non-Profit 1).

\section{Discussion}

Our main finding on student learning in this study focused on students developing perseverance and adaptability, and character-building skills such as: curiosity and imagination, oral and written communication, collaboration, and critical thinking and problem-solving.

One of the main character-building skills mentioned during the interviews was perseverance. The instructors/teachers encouraged students to make mistakes and take risks. The students' learning experience, the "making process" as well as the product made were important in each STEAM program. Students documented the "making process" and shared their thinking through presentations, written documentation, photos and videos at Non-Profit 1 and at both in-school sites.

The findings also support Conley et al.'s (2014) claims that integrating the arts into STEM promotes communication and critical-thinking skills, and it helps students to develop a global perspective.

\section{Perseverance, adaptability, failure and iteration}

At the non-profit and in-school sites, students appeared to learn and practice perseverance and adaptability when going through the design-inquiry process of plan-design-make-testredesign and repeat. The teacher librarian at In-School 2 said that one of the greatest benefits of STEAM was "developing mindsets, developing perseverance and grit in an openness to try new things." She explains "I think that's one of the things that we're trying to build is perseverance and risk taking and grit and ... it's more about the learning ... [and] the learning is more about the process" (In-School 2). Encouraging students to persevere by taking risks, making mistakes, and by developing grit and resilience was evident in all the STEAM programs we studied. We observed that at all the nonprofit and in-school sites, the instructors/teachers also seemed to create an environment in which students felt comfortable making mistakes and taking risks because students had a positive teacher-student relationship. This appeared to be unrestricted (e.g. not restricted to a specific time or place) when the students were asking questions and interacting with the teacher.

\section{Transferable skills}

At all the research sites, students learned character-building skills (21st century skills) which were "transferable skills so they can take [it] with them to the next grade level" and use those skills in another context (teacher librarian, In-School 1). The findings on students learning skills that are transferrable is in line with the literature on the benefits of STEAM learning; in STEAM education students are able to transfer their knowledge across disciplines and creatively solve problems in another context (Gess, 2017; Liao, 2016).

Industrial, political and educational leaders rally for students to develop workforce competencies by “"promoting deeper' learning through skills such as problem solving, critical thinking, and collaboration” (Allina, 2018, p. 80). A Grade 5 teacher at In-School 1 echoed this 
JRIT

13,1

\section{4}

by saying "this is like 21st Century learning for kids." According to Hughes (2017), students need these character-building skills to "develop and apply for successful learning, living and working" (p. 102). The STEAM programs in this study teach character-building skills, such as "critical thinking and problem solving; collaboration and communication; and creativity and innovation" (Liao et al., 2016, p. 29) that can be transferred to another context, such as in the home, in high school, in post-secondary education and in the workforce.

\section{Conclusion}

Politicians and industry leaders tend to focus on the academic skills and career paths of students whereas in the STEAM programs in this study the instructors/teachers valued the process and the character-building skills that students developed. The findings are in line with Kolb and Kolb's (2005) guiding principle of the experiential learning theory which states that learning is best conceived as a process. For example, students were given the opportunity to document the making process to develop a deeper understanding. The focus on developing students' perseverance, collaborative and critical thinking skills is in line with Blikstein's (2013) assertion that if "the aim is efficiency ... it could have undermined students' willingness to persist through difficult problems" (p. 15) or could encourage them to "prematurely [abort] design elements that they deemed too difficult" (p. 14). In these STEAM activities students were encouraged to persevere by taking risks, making mistakes, and by developing the grit to persevere on multistep tasks. All of the lessons and units studied by the researchers appeared to be student-centered and to incorporate student interests. For example, the activities started with "low floor" entry-level questions such as those that made students curious or in which they wrote about their design plans. In addition, the activities appeared to be "high ceiling" as students moved on to fabricate, program, solder and wire their designs. The activities were also "wide walls" because they allowed multiple ways to approach a problem and encouraged both student creativity and innovation (Gadanidis et al., 2011; Gadanidis, 2015).

In this paper, we highlight the findings from the interviews, observations, curriculum documents and the focus group as well as the cross-case findings among the different data sources. This study has implications for future research such as investigating the design and implementation of STEAM programs that promote the teaching and learning of workplace and transferable skills. Although the findings provide deeper insight into STEAM education, we offer several possibilities for future research. This study provides a snapshot of the STEAM programs, in which the data were collected over four months. In order to provide even more insight into this phenomenon of STEAM education there need to be more research sites, and data that are collected over a longer period of time. Specifically, we need to study how these character-building skills transfer to other contexts and different subject areas over time. Educators, researchers and policymakers have an invested interest in assessment and documentation; it would also be beneficial to gain more insight on how educators assess and document student learning in these STEAM programs.

The scope of this paper focused mainly on the character-building skills, but the STEAM curriculum also provided students with the opportunity to learn academic skills. The instructors/teachers focused on providing students with the opportunity to engage in rich tasks and authentic experiences. The STEAM programs and activities extended students' engagement beyond simple and quick explorations of robots, programming software and fabrication tools, could be attributed to these nonprescriptive settings (i.e. nonclassroom contexts timetabled for a single STEAM subject and/or makerspace environment). The findings support Blikstein's (2013) claim that educators should avoid "quick demonstration projects" and instead promote "multiple cycles of design" through "powerful interdisciplinary projects" (p. 18) that encourage students to transfer their knowledge across disciplines and solve problems in another context (Gess, 2017; Liao, 2016). The setting 
of the in-school STEAM programs in the library learning commons (e.g. makerspace) or in the after-school program, in particular, outside the constraints of single-subject specific lesson, specific curriculum standard and expectations, concept or discipline, appeared to enhance the students' overall learning experience, making the experience deep and more meaningful. For educators, researchers and policymakers, the goal should be to seek to provide STEAM learning experiences in classrooms for all learners. This would encourage students to engage in and learn, even if occasionally, in ways that transcend their knowledge across individual disciplines and teach them domain-specific, domain-general/interdisciplinary and other transdisciplinary learning skills.

\section{References}

Allina, B. (2018), "The development of STEAM educational policy to promote student creativity and social empowerment", Arts Education Policy Review, Vol. 119 No. 2, pp. 77-87.

Amory, A. (2014), "Tool-mediated authentic learning in an educational technology course: a designedbased innovation”, Interactive Learning Environments, Vol. 22 No. 4, pp. 497-513.

Arthur, J., Waring, M., Coe, R. and Hedges, L.V. (2012), Research Methods and Methodologies in Education, Sage, Los Angeles, CA.

Blikstein, P. (2013), "Digital fabrication and 'making' in education: the democratization of invention", FabLabs: Of Machines, Makers and Inventors, Vol. 4, pp. 1-21.

Conley, M., Douglass, L. and Trinkley, R. (2014), "Using inquiry principles of art to explore mathematical practice standards", Middle Grades Research Journal, Vol. 9 No. 3, pp. 89-101.

Costantino, T. (2018), "Steam by another name: transdisciplinary practice in art and design education", Arts Education Policy Review, Vol. 119 No. 2, pp. 100-106.

Cousin, G. (2005), "Case study research”, Journal of Geography in Higher Education, Vol. 29 No. 3, pp. $421-427$.

Gadanidis, G. (2015). "Young children, mathematics, and coding: a low floor, high ceiling, wide walls environment", Cases on Technology Integration in Mathematics Education, IGI Global, Hershey, PA, pp. 308-329.

Gadanidis, G., Hughes, J. and Cordy, M. (2011), "Mathematics for gifted students in an arts-and technology-rich setting", Journal for the Education of the Gifted, Vol. 34 No. 3, pp. 397-433.

Gall, M.D., Gall, J.P. and Borg, W.R. (2007), Educational Research: An Introduction, Pearson Education, Boston.

Gess, A.H. (2017), "STEAM education: separating fact from fiction", Technology and Engineering Teacher, Vol. 77 No. 3, pp. 39-41.

Halverson, E.R. and Sheridan, K.M. (2014), "The maker movement in education”, Harvard Educational Review, Vol. 84 No. 4, pp. 495-504.

Hughes, J.M. (2017), "Digital making with 'At-Risk' youth”, The International Journal of Information and Learning Technology, Vol. 34 No. 2, pp. 102-113.

Kafai, Y., Proctor, C. and Lui, D. (2019), "From theory bias to theory dialogue: embracing cognitive, situated, and critical framings of computational thinking in K-12 CS education", International Computing Education Research Conference (ICER '19), August 12-14, 2019, ACM, Toronto, ON, Canada, New York, NY, USA, p. 9, doi: 10.1145/3291279.3339400.

Kolb, A. and Kolb, D.A. (2005), Experiential Learning Theory Bibliography, Experience Based Learning Systems, Cleveland, $\mathrm{OH}$.

Liao, C. (2016). "From interdisciplinary to transdisciplinary: an arts-integrated approach to STEAM education", Art Education, Vol. 69 No. 6, pp. 44-49.

Liao, C., Motter, J.L. and Patton, R.M. (2016), "Tech-savvy girls: learning 21st-century skills through STEAM digital artmaking", Art Education, Vol. 69 No. 4, pp. 29-35. 
JRIT 13,1

Papert, S. (1980), Mindstorms: Children, Computers, and Powerful Ideas, Basic Books, New York, NY.

Reeves, T.C., Herrington, J. and Oliver, R. (2004), "A development research agenda for online collaborative learning”, Educational Technology Research and Development, Vol. 52, pp. 53-65.

Stake, R. (2005), "Qualitative case studies", in Denzin, N.K. and Licoln, Y.S. (Eds), The Sage Handbook of Qualitative Research, 3rd ed., Sage, London, pp. 443-466.

Yin, R.K. (2004), Case Study Methods, AERA, or Yin, R.K. (2009). Chapter 2. Case Study Research: Design and Methods, London, Sage, available at: http://www.cosmoscorp.com/Docs/ AERAdraft.pdf.

About the authors

Marja G. Bertrand is a MA graduate from Western University and a teacher in Mathematics, Science, Biology, Chemistry and Physics. Presently, she is teaching for the local school board Grade 9, 10 and 11 Mathematics and working as a Senior Research Assistant at Western University. She is passionate about teaching and learning. She has presented at several conferences, seminars and workshops on STEM/STEAM education in Canada and abroad. She has also received several graduate awards from the Faculty of Education for her research on STEM/STEAM education. Specifically, the Art Geddis Memorial Award for her use of reflective practice as a critical lens to analyze the mathematics and science learning in the curriculum and pedagogy of the STEAM programs. She was also awarded the Joan Pedersen Memorial Graduate Award for her contribution to the "Early Years" education research. Her research interests are in STEM/STEAM education, Makerspaces, Designed-Based Learning and Computational Thinking tools. Marja G. Bertrand is the corresponding author and can be contacted at: mgbertra@uwo.ca

Immaculate K. Namukasa is an Associate Professor of the Faculty of education and distinguished teaching fellow with the Center for Teaching and Learning from 2017 to 2020 at Western University in Ontario, Canada. She joined the Faculty of Education at Western from the University of Alberta, where she completed her Doctoral work in the department of Secondary Education. She is a past journal editor for the Ontario Mathematics Gazette - a magazine for teachers and educators and a current editor of the Math + code 'Zine. Namukasa collaborates with teachers in four public school boards, in one private school system, and with researchers and teachers in Canada, China, Thailand and Africa. Namukasa's current research interests lie in mathematics teacher education and professional development, integration of technology and computational thinking in mathematics education, mathematics learning tools, resources and activities, and curriculum and pedagogical reforms.

For instructions on how to order reprints of this article, please visit our website:

www.emeraldgrouppublishing.com/licensing/reprints.htm

Or contact us for further details: permissions@emeraldinsight.com 